\title{
26429 - FACTORS AFFECTING PERIOPERATIVE TRANSFUSION DECISIONS FOR CORONARY ARTERY BYPASS PATIENTS: A NATIONAL SURVEY.
}

\author{
Nadine Shehata MSc, Kumanan Wilson, MSc; CDavid Mazer, MD; George \\ Tomlinson, Streiner David, PhD; St. Michael's Hospital, University Of Toronto, \\ Toronto, ONTARIO, Canada
}

INTRODUCTION: A high proportion of patients having cardiac bypass surgery receive red cell transfusions. Decisions about when to transfuse patients having surgery for coronary artery disease may impact on patient morbidity and mortality. There are no published data about the factors that influence physicians' decisions to transfuse red blood cells to these patients. The objectives of this study were to determine the hemoglobin concentration for transfusion, and the factors that influence physicians' perioperative transfusion decisions for coronary artery bypass patients.

METHODS: We conducted a cross-sectional study using pre-tested, self-administered, mailed questionnaires sent in 2004 to all cardiac surgeons and anesthesiologists in Canada who participate in coronary artery bypass surgery. The questionnaire included four intraoperative and four postoperative vignettes. Factors assessed included patient age, sex, cardiac index, and myocardial ischemia and physician characteristics. Univariate analysis and mixed effects regression model were used to analyze the data. RESULTS: The response rates were 70.5\% (345/489) for the intraoperative and 60.7\% (297/489) for the postoperative case scenarios. Responses were received from anesthesiologists in all 32 cardiac centres in Canada and from cardiac surgeons in 30/32 centres. The mean hemoglobin concentrations for transfusion were $69.5 \mathrm{~g} / \mathrm{L}$ for the intraoperative case scenarios and $72.0 \mathrm{~g} / \mathrm{L}$ for the postoperative case scenarios. The hemoglobin transfusion thresholds for 5 of the 24 case scenarios are illustrated in the Table. Older age, the presence of myocardial ischemia, and a low cardiac index were factors that increased the hemoglobin concentration for transfusion $(\mathrm{p}<0.0001)$. The hemoglobin concentration for transfusion did not differ significantly according to physician age, sex, years in practice, bypass cases /individual/year, or bypass cases/centre/year. Physicians working in academic institutions selected lower hemoglobin concentrations than physicians in community settings for the intraoperative case scenarios $(\mathrm{p}=0.04)$, and physicians involved in postoperative transfusion decisions selected lower hemoglobin concentrations for the postoperative case scenarios $(\mathrm{p}=0.01)$. Physicians ranked myocardial ischemia as the most significant factor affecting their transfusion decisions.

DISCUSSION: Factors such as the presence of a low cardiac index, myocardial ischemia and older age increase the hemoglobin concentrations at which physicians transfuse coronary bypass surgery patients. Future studies are required to elucidate whether transfusions based on these variables affect patient morbidity and mortality. 
FACTORS AFFECTING PERIOPERATIVE TRANSFUSION DECISIONS FOR CORONARY ARTERY BYPASS PATIENTS: A NATIONAL SURVEY. Shehata N,

Wilson K, Mazer CD, Tomlinson G, Streiner D, Hebert P, Naglie G.

\section{TABLE}

Mean Hemoglobin Concentrations (Standard Deviation) $(\mathrm{g} / \mathrm{L})$ For the Female Scenario

\begin{tabular}{|l||l|l|}
\hline Description & Intraoperative & Postoperative \\
\hline
\end{tabular}

\begin{tabular}{|l|l|l|}
\hline 55 year old. cardiac index $>2.5$, no myocardial ischemia & $69(8)$ & $72(7)$ \\
\hline
\end{tabular}

\begin{tabular}{|l||l|l|}
\hline 55 year old, cardiac inde $>2.5$ and myocardial ischemia & $78(10)$ & $81(9)$ \\
\hline
\end{tabular}

\begin{tabular}{|l|l|l|}
\hline 55 year old, cardiac index $<2$, no myocardial ischemia & $79(10)$ & $80(9)$
\end{tabular}

\begin{tabular}{|l|l|l|}
\hline 55 year old, cardiac index $<2$ and myocardial ischemia & $85(11)$ & $87(9)$
\end{tabular}

\begin{tabular}{|l|l|l|}
\hline 75 year old, cardiac index $>2.5$ & $74(8)$ & $76(7)$ \\
\hline
\end{tabular}

